Supporting information for:

\title{
Computational studies of experimentally observed structures of sulfur on metal surfaces
}

\author{
Dominic R. Alfonso \\ National Energy Technology Laboratory, U. S. Department of Energy, \\ Pittsburgh, PA 15236
}


Fig. S1: Top view of the (111) surfaces showing the adsorption sites. The $(2 \times 2)$ and $(\sqrt{3} \times \sqrt{3})$ unit cells applied in the calculations are marked.

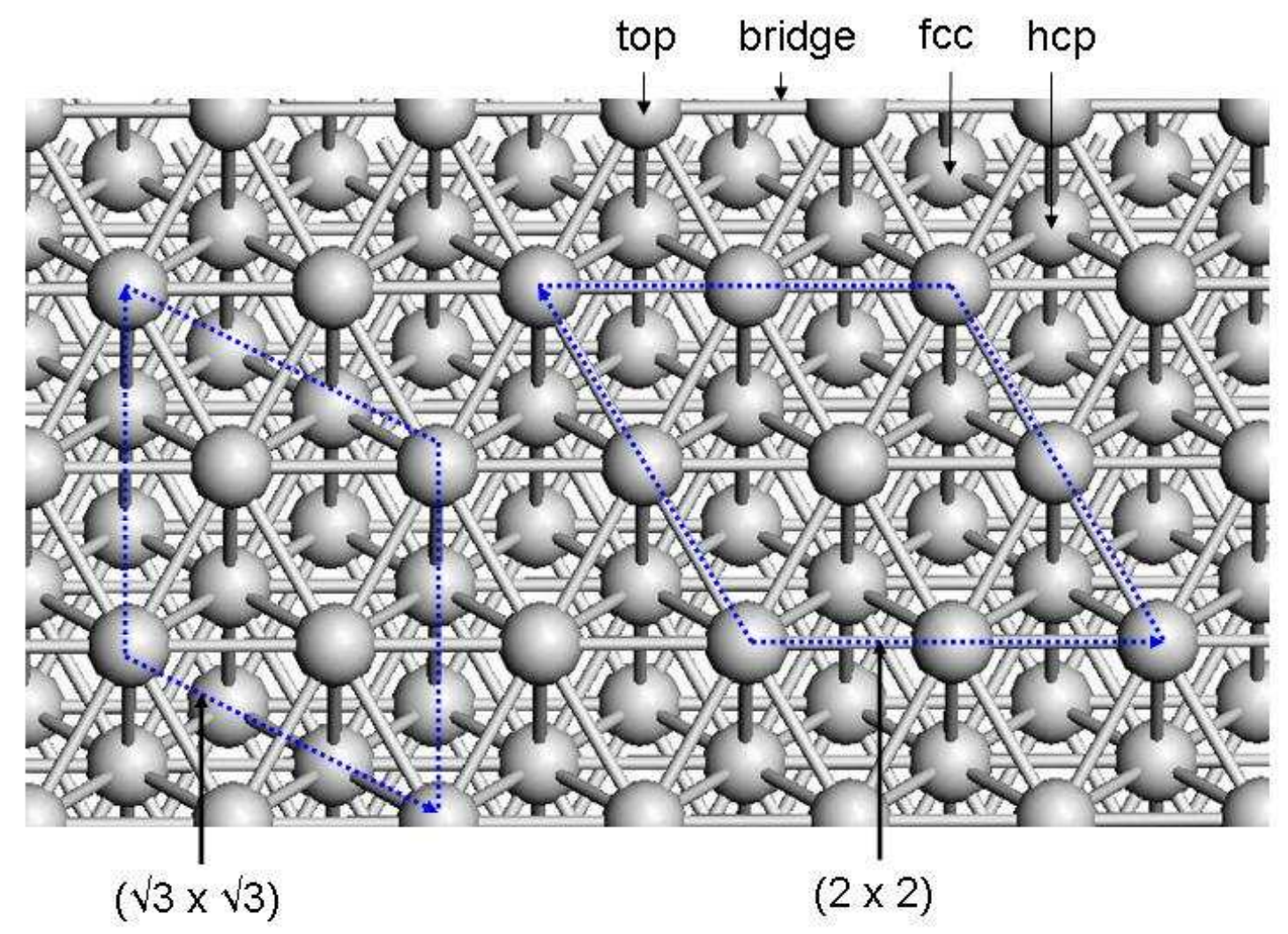


Fig. S2: Top view of the $(1000)$ surfaces showing the adsorption sites. The $c(\sqrt{3} \times 5),(2 \times 2)(\sqrt{3} \times \sqrt{3})$ unit cells applied in the calculations are marked.

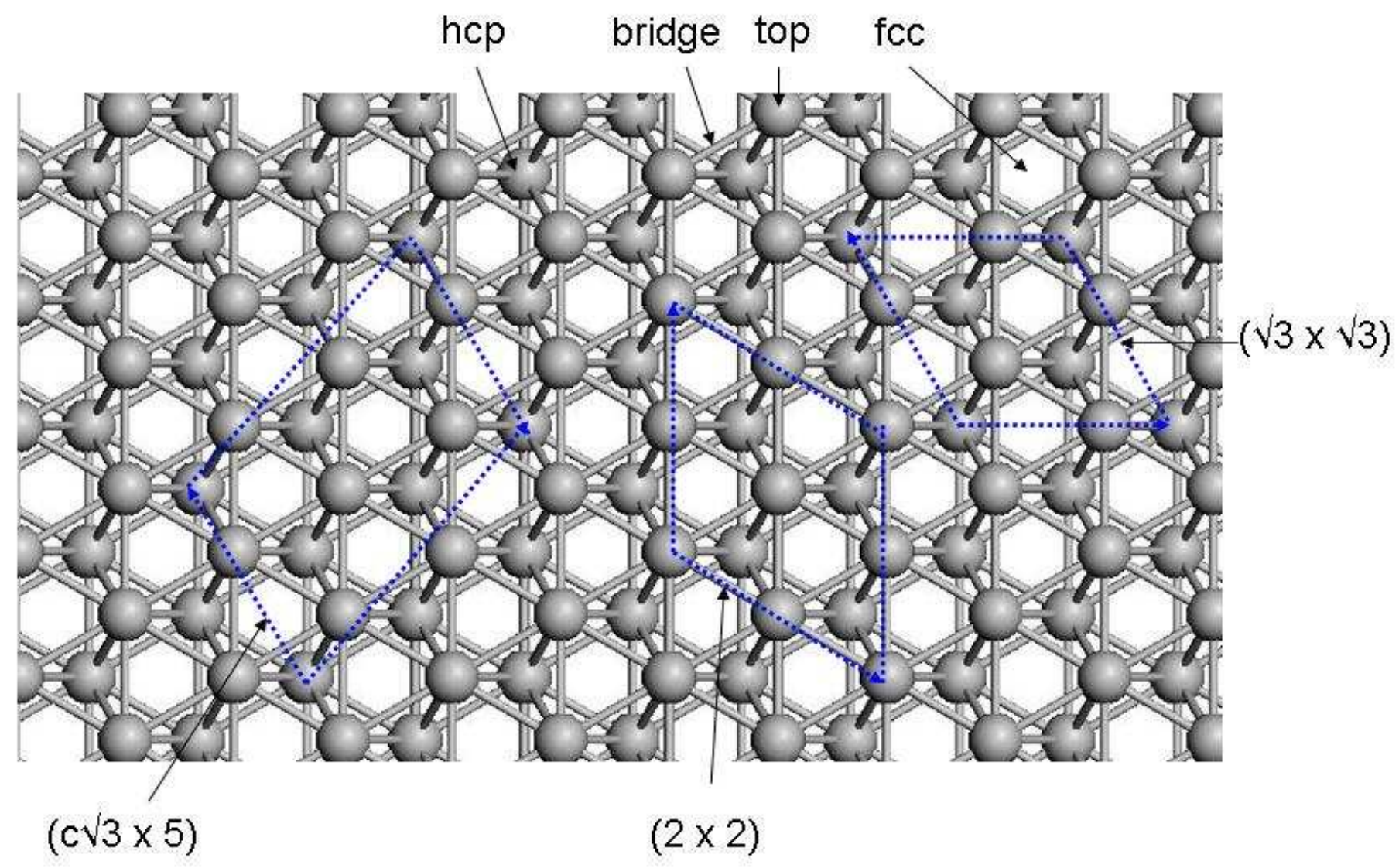

